\title{
Correction to: Extraction and characterization of gelatin developed from camel bones
}

\author{
A. A. Al-Hassan ${ }^{1}$ - A. M. Abdel-Salam ${ }^{2}$ - F. Al Nasiri ${ }^{3}$ H. M. Mousa ${ }^{1} \cdot$ Abdorreza Mohammadi Nafchi $^{4,5}$
}

Published online: 6 July 2021

○) Springer Science+Business Media, LLC, part of Springer Nature 2021

\section{Correction to:}

\section{Journal of Food Measurement and Characterization} https://doi.org/10.1007/s11694-021-01029-y

The original version of this article, unfortunately, contained a mistake. The second and third author's affiliations mixed up and the correct affiliations are as follow:

A. M. Abdel-Salam

Dairy Science Department, National Research Centre, Dokki, Cairo, 12622, Egypt

F. Al Nasiri

Saudi Food and Drug Administration, Riyadh, 13312, Saudi Arabia

Also, the article has two corresponding authors, A. A. Al-Hassan and Abdorreza Mohammadi Nafchi

These errors do not affect any results or conclusions.

The original article has been corrected.

The original article can be found online at https://doi.org/10.1007/ s11694-021-01029-y.

\section{A. A. Al-Hassan}

ahsn@qu.edu.sa

$\triangle$ Abdorreza Mohammadi Nafchi amohammadi@usm.my

1 Food Science and Human Nutrition Department, College of Agriculture and Vit. Medicine, Qassim University, Burydah 51452, Saudi Arabia

2 Dairy Science Department, National Research Centre, Dokki, Cairo 12622, Egypt

3 Saudi Food and Drug Authority, Jeddah 22235-4294, Kingdom of Saudi Arabia

4 Department of Food Science and Technology, Islamic Azad University, Damghan Branch, Damghan, Iran

5 Food Biopolymer Research Group, Food Technology Division, School of Industrial Technology, Universiti Sains Malaysia, Minden, 11800 Penang, Malaysia
Publisher's Note Springer Nature remains neutral with regard to jurisdictional claims in published maps and institutional affiliations. 